\title{
TUCÍDIDES 1.22: KTHMA A SER OUVIDO
}

\author{
Sandra Lúcia Rodrigues da Rocha*
}

Resumo: This paper argues that reading aloud was the method of reception for Thucydides' text in early fourth century and that the historian was fully aware that his addressees were a listening audience. Whereas it is usually agreed that Thucydides' reader is expected to be highly critical of the events the prose writer narrates, such a level of criticism might not necessarily exclude the reception of his text by means of reading aloud, discussion and memorization. By examining Thucydides' text, the paper explores the metaphor in ktema es aei ... akouein ksynkeitai (1.22) as a subtle reference to the monumental imagery related to inscriptions on stone and to the way these inscriptions were read.

Palavra-chave: Tucídides, Prosa, Leitura, Audiência, Ktema.

Quando a prosa historiográfica começou a ser escrita na Grécia, havia já uma longa tradição de recepção de textos por meio de recitação ou leitura em voz alta. A maioria deles eram narrativas poéticas que buscavam proporcionar prazer ao ouvinte; ao mesmo tempo, serviam como instrumento de preservação da identidade cultural grega (Kahn, 2003, p. 148 e ss.). No século $\mathrm{V}$, o tratado em prosa tinha começado a competir com os poemas, mantendo a divulgação para grandes audiências por meio de leituras públicas ou discussões particulares com recurso à memorização (Kahn, 2003, p. 152). Assim, a prosa começava a ser considerada objeto de instrução a ser transmitido oralmente em palestras e discussões masculinas ${ }^{1}$. Apesar de ser ainda controversa a hipótese de que os textos dos historiadores clássicos tenham sido objetos de performances de prosa ${ }^{2}-$ o que seguramente ocorreu com muitos tratados hipocráticos -, esse artigo pressupõe que a história de Tucídides constitui mais uma narrativa a participar desse cenário em que textos, para serem transmitidos, dependiam sobretudo da voz de alguém.

Tucídides escreveu sua obra em um contexto de práticas de leitura que envolviam a manipulação de materiais bem diferentes dos usados para o livro moderno. A escrita sem espaços, a natureza e o formato do papiro, que se transformava em vários rolos para abrigar a escrita de textos extensos, além do hábito grego de debater e aprender através de discussões orais, favoreceram a leitura em voz alta na Grécia clássica. A imagem que Tucídides faz de seu leitor e que se depreende de seu texto é, portanto, a de alguém que pronunciava as palavras em voz alta - o que, naturalmente, não exclui o fato de que pudesse haver quem o tentasse ler silenciosamente. Mas há evidências na História da Guerra do Peloponeso de que Tucídides não tinha em mente esse possível leitor silencioso ${ }^{3}$, e ele deixa isso claro mais de uma vez em seus capítulos conhecidos como metodológicos. Primeiro, seus leitores não estariam enganando-se se aceitassem as conclusões a que ele chegou a partir do que seus informantes lhe haviam contado, e uma das razões dessa segurança é, diz ele, que seu relato não teria nem o adornamento das histórias de poetas nem o tom dos discursos de logógrafos, que preferiam agradar à audiência

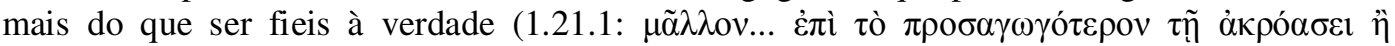
$\dot{\alpha} \lambda \eta \theta \dot{\varepsilon} \sigma \tau \varepsilon \rho o v)$. Tucídides acrescenta que estes tratavam de acontecimentos cuja veracidade não

\footnotetext{
*Professora de Língua e Literatura Gregas da Universidade de Brasília.

${ }^{1}$ Veja-se a conhecida passagem em Xenofonte, Memorabilia I.6.14, em que Sócrates, na companhia de seus amigos, "desenrola" livros de homens sábios.

${ }^{2}$ Veja-se e.g. Flory (1980), com relação a Heródoto; Yaginuma (1995), quanto a Tucídides; e Thomas (2000, p. 249 e ss.), para um paralelo entre as características adequadas a performance em Heródoto e em autores hipocráticos.

${ }^{3} \mathrm{O}$ leitor silencioso de Tucídides é postulado em algumas abordagens contemporâneas: Yaginuma (1995, p. 132) argumenta que o (difícil) estilo de Tucídides sugere que ele visava, deliberadamente, a um leitor silencioso; segundo Bakker, "the war of the Peloponnesians and Athenians is a "readerly" text, a discourse that is meant for direct ingestion from the written page, without the mediation of a reading voice" (2006, p. 109); para Edmunds (1993, p. 832), Tucídides renuncia à publicação oral característica de autores como Protágoras, Heródoto e escritores de discursos para tribunais.
} 
podia ser verificada, e seus textos estavam cheios de elemento fictício - $\tau$ ò $\mu v \theta \tilde{\omega} \delta \varepsilon \varsigma$. Todas essas advertências, no início da obra, dirijem-se a uma audiência que está, naturalmente, acostumada a ouvir poetas e logógrafos, pois, do contrário, elas não poderiam surtir efeito. O problema, portanto, não está em ouvir, mas no que poetas e logógrafos têm a dizer. É uma distinção de conteúdo que Tucídides clama para sua obra, quando ele a define em 1.22.4 por oposição às

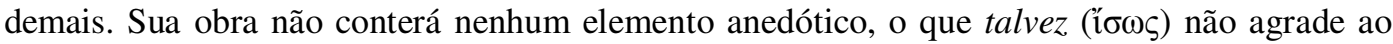

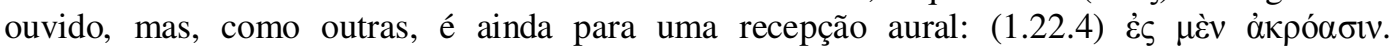
Obviamente, as audiências gregas são mais complexas do que esquematicamente, às vezes, as concebemos: o mesmo grupo de ouvintes certamente desfrutava tanto de histórias anedóticas quanto de narrativas sérias em diferentes momentos e contextos ${ }^{4}$. E o advérbio î $\sigma \omega \varsigma$ faz uma grande diferença, uma vez que Tucídides parece não estar muito certo de que $\tau$ ò $\mu \grave{\eta} \mu v \theta \tilde{\omega} \delta \varepsilon \varsigma$ pudesse, definitivamente, excluir algum prazer ao se ouvir sua obra.

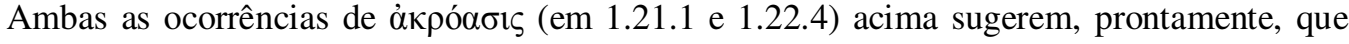
Tucídides está se referindo a pessoas que ouviriam sua obra fosse por meio de própria leitura em voz alta fosse por meio da leitura de outrem. Mas é o último enunciado, 1.22.4, que tende a causar maior estranhamento, quando se assume que Tucídides, ao considerar sua obra como um

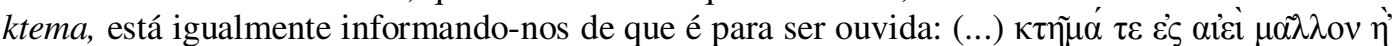

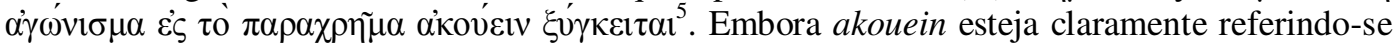
à obra de Tucídides, há uma tendência a se ignorar a relação entre ktema e akouein, e a se criar uma correspondência direta entre ktema e escrita, por um lado, e agonisma e akouein, por outro $^{6}$. Assim, Tucídides, ao associar sua obra à imagem de uma aquisição para sempre, estaria manifestando também sua percepção quanto à potencial durabilidade e perenidade do meio escrito. É possível. O que me parece impossível é que essa percepção plausível da materialidade da escrita por meio da qual se pudesse vislumbrar maior permanência no tempo excluísse, na mentalidade da época, a recepção aural, com recurso à voz. O fato é que a interpretação de que ktema não pode estar relacionado a akouein fica evidente em muitas traduções que naturalmente dissociam as duas palavras em 1.22.4. Por exemplo:

a. "It is a possession for all time, not a competition piece to be heard for the moment, that has been composed" (Lattimore);

b. "My work is not a piece of writing designed to meet the taste of an immediate public, but was done to last forever" (Warner).

c. "Ils [les faits rapportés] constituent un trésor pour toujours, plutôt qu'une production d'apparat pour un auditoire du moment" (Romilly).

d. "An everlasting possession, rather than a prize of composition which is heard for the moment" (Hornblower, 1991, p. 617).

e. "And it is compiled rather for an everlasting possession than to be rehearsed for a prize" (Hobbes).

f. "In fine, I have written my work, not as an essay which is to win the applause of the moment, but as a possession for all time" (Crawley).

g. "Constituem mais uma aquisição para sempre que uma peça para um auditório do momento" (Anna Lia Amaral de Almeida Prado)

\footnotetext{
${ }^{4}$ Quanto a mudanças nas expectativas da audiência de acordo com o gênero, ver Pelling (2000, p. 1 e ss.).

${ }^{5}$ Hornblower admite que parte da História da Guerra do Peloponeso seja adequada à recitação, como o relato da stasis em Córcira (1991, p. 60-61). Ele interpreta $\mu \tilde{\alpha} \lambda \lambda$ ov comemoração particular (p. 119). Em seu último comentário, publicado recentemente, Hornblower apresenta uma lista de passagens adequadas à recitação, do livro 5 ao 8 (2008, p. 31).

${ }^{6}$ Crane menciona ktema es aiei e negligencia akroasis, ao defender que a obra de Tucídides é designada primeiramente para "um leitor reflexivo", e concebida como um "artefato escrito" - como marcas arranhadas em um papiro, desenrolado e escrutinado pelo olho (não pelo ouvido, eu entendo) (1996, p. 7). Bakker, embora certo ao considerar que Tucídides contemplava um publico leitor maior do que o de uma audiência momentânea, também interpreta akouein como relacionado, exclusivamente, a agonisma es to parakhrema (2006, p. 109). Na mesma linha de raciocínio, Yaginuma diz o seguinte: “he [Thucydides] mentions ákov́cıv only in

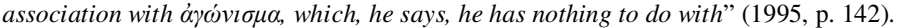

${ }^{7}$ Hornblower, às vezes, traduz as passagens que comenta; essa tradução encontra-se no primeiro volume dos Comentários de Hornblower.
} 
Nessas traduções, a proximidade de agonisma es to parakhrema e akouein tem influenciado a interpretação dos tradutores ${ }^{8}$. É possível, porém - e a língua grega também permite isto -, que agonisma e ktema estejam estabelecendo a mesma relação com o verbo akouein - o que não equivale à interpretação clássica da passagem, uma vez que tendemos a perceber es to parakhrema akouein como uma unidade, talvez seguindo, muito apressadamente, a entrada de parakhrema no respeitável dicionário de Liddell e Scott. Mas esse dicionário, sugestivamente, usa como abonação para parakhrema a passagem da obra de Tucídides, de modo que podemos suspeitar da intrínseca conexão semântica entre agonismalparakhrema e akouein em traduções de língua inglesa, já que tradutores podem simplesmente estar operando dentro de um ciclo vicioso criado pela entrada do dicionário.

Observando-se a sintaxe do trecho, uma outra leitura parece plausível. Há um paralelismo bastante evidente entre agonisma e ktema, os quais expressam, ambos, noções abstratas, com o sufixo $-m a^{9}$. Respectivamente, os dois termos significam aquilo que é objeto de uma competição (do verbo agonizo) e aquilo que é objeto da posse de alguém (do verbo ktaomai). Ambos os substantivos designam o objeto envolvido na ação verbal de um modo geral: ktema usualmente tem como referente bens materiais, como uma casa ou um monumento, e agonisma, uma peça teatral ou um discurso, por exemplo, mas, em essência, seus significados são abstratos. Em 1.22.4, o referente de ktema é a obra de Tucídides, de modo que o que está sendo dito é que seu relato, constituído de muitas partes, está reunido (sunkeitai ${ }^{10}$ ) como uma aquisição a ser ouvida (akouein) em qualquer momento novamente (es aiei). Não deve ser considerado como se fosse um objeto que toma parte em um competição (agon, agonizo), que, em geral, é ouvido apenas uma vez, no único momento do debate. Na verdade, a oração desenvolve-se com paralelismo sintático: a comparação em $\mu \tilde{\alpha} \lambda \lambda$ ov ì contrasta a sequência

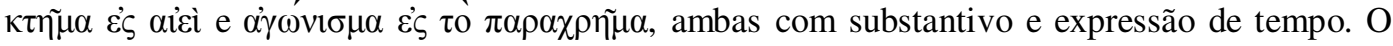
infinitivo akouein funciona sintaticamente, tanto para ktema quanto para agonisma, como infinitivo de oração final e consecutiva ${ }^{11}$. Uma tradução literal poderia ser algo como: "Minha obra está reunida para ser ouvida como uma aquisição para sempre mais do que como um objeto de competição para o momento." Um argumento contrário pode aventar a impossibilidade de se ouvir algo como ktema, raciocínio que, então, deve-se aplicar também a agonisma, pois esses dois termos apresentam significados abstratos: não é o agonisma ou o ktema que se ouve em circunstância alguma, mas os logoi que se apresentam como tais. A metáfora de Tucídides implica que ambos são possíveis, i.e. pode-se ouvir um logos tanto como ktema quanto como agonisma. E veremos a seguir que, ao chamar seu logos de ktema, Tucídides em nada está sendo original para os gregos de seu tempo.

\section{A OBRA DE TUCÍDIDES COMO MONUMENTO: COMO DECRETO?}

A metáfora em ktema e akouein pode ter funcionado perfeitamente para Tucídides e seus contemporâneos. Parece que o substantivo ktema, em contraste com seu significado, em geral associado a posses materiais, produzia boas metáforas ao evocar noções abstratas, especialmente comportamentos éticos elogiáveis. O termo é frequiente nos trágicos, em máximas de virtudes. Em Eurípides, temperança e respeito aos deuses são a mais sábia aquisição dos

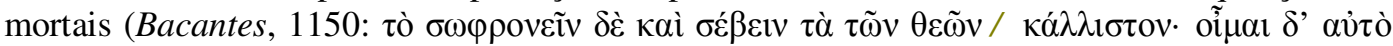

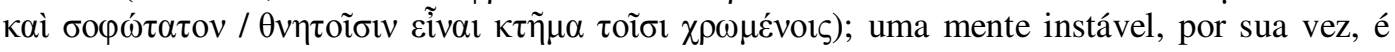

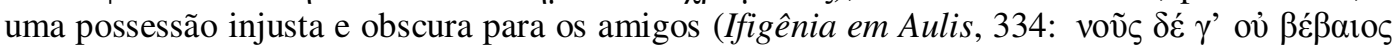

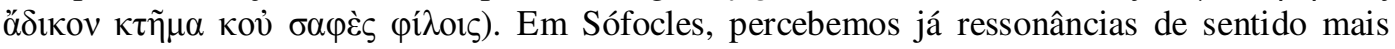

\footnotetext{
${ }^{8}$ As referências de cada tradução citada encontram-se no final do artigo, junto às demais referências.

${ }^{9}$ Para uma abordagem exaustiva ao sufixo - ma, ver Chantraine (1933, p. 175-190).

${ }^{10}$ Observe-se o uso do prefixo syn-, que salienta o significado de "coisas a serem reunidas", diferentemente de keimai, que foca somente a permanência no tempo ou a ausência de movimento, a situação estática.

${ }^{11} \mathrm{Na}$ construção em Tucídides, pode-se cogitar a omissão de um acusativo como sujeito de akouein, que poderia ser um pronome indefinido (tina): "para alguém ouvir". Quanto a detalhes acerca dessa construção, ver Cooper (1998, p. 791-2).
} 
próximo ao uso de ktema em Tucídides: a palavra, o conselho, pode ser uma possessão valiosa,

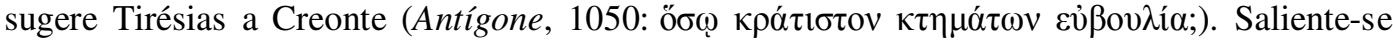
que aqui se trata da palavra oral, proferida pelo profeta. Mas é, curiosamente, na retórica de Isócrates que encontraremos a associação tucidideana de ktema com akouein de modo mais explícito. No discurso A Demônico ${ }^{12}$, Isócrates exorta o jovem a considerar que os preceitos ouvidos ( $\tau \tilde{\omega} v \dot{\alpha} \kappa o v \sigma \mu \alpha ́ \tau \omega v)$ são muito melhores do que as maiores fortunas, pois estas desaparecem rapidamente, enquanto aqueles duram por muito tempo; pois a sabedoria é a única

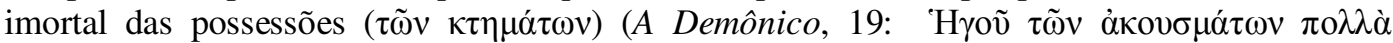

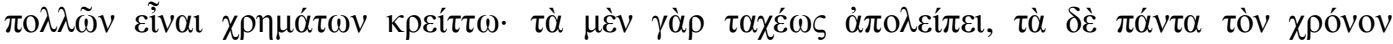

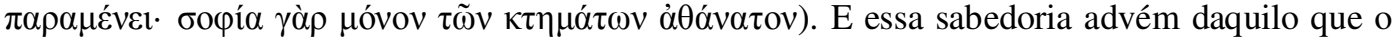
jovem ouve. Curiosamente, Isócrates associa às palavras ouvidas a um efeito duradouro sobre o aprendiz. Não é, portanto, o meio de transmissão o que as faz durarem, mas seu conteúdo repleto de sabedoria. É certamente com esse sentido que Tucídides usa ktema para a sua obra: assim como é imortal a sabedoria adquirida pelos jovens que a buscam nas lições (ouvidas) da prosa isocrática, hão de ser imortais também os ensinamentos da obra tucidideana, que poderão ser ouvidos inúmeras vezes no futuro $\left(\varepsilon \dot{\zeta} \zeta \alpha^{i \varepsilon i}\right)^{13}$.

Visto nesse contexto, não me parece que o ktema de Tucídides implique, necessariamente, uma referência à natureza escrita de seu relato, como algumas leituras têm insistido. Além

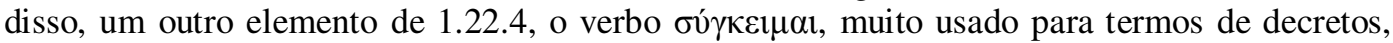
estimula outras interpretações. Ora, os gregos do período clássico eram acostumados a ouvir, no tribunal ou na assembléia, a leitura em voz alta de suas leis ${ }^{14}$ e decretos inscritos em stelai. De fato, a descrição que Tucídides faz de sua obra em 1.22 traz traços de uma herança inscricional, que evoca uma imagem monumental. Já para Dionísio de Halicarnasso, o historiador escrevera um logos como se erigisse um monumento, uma característica distintiva do seu ofício que teria afetado também seu estilo, em contraste com o de oradores: a linguagem de Tucídides teria sido laboriosamente arranjada para expressar o desejo de que seu texto fosse recebido como monumento e possessão eterna ${ }^{15}$. Além disso, Moles verificou a similaridade entre a expressão, em 1.22.4, hosoi boulesontai... skopein e toi boulomenoi skopein, esta última presente em inscrições atenienses do século V e mais recentes (Moles, 1999; Thomas, 1989, p. 61, n. 151). Moles também constatou que a abertura da História da Guerra do Peloponeso se parece muito com uma fórmula inscricional, uma vez que a referência à escrita, em aoristo, indicando o texto como um produto concluído (Tucídides 1.1: Thoukydides... ksynegrapse), lembra algumas inscrições memoriais (Moles, 1999) em que a frase inscrita está igualmente em aoristo (Bakker, 2006, p. 114-15) ${ }^{16}$. O verbo-base para synkeimai, keimai - frequentemente usado em inscrições funerais -, é uma outra indicação do imaginário monumental subjacente a 1.22.4, embora, nesse caso, talvez seja mais correto relacioná-lo às práticas da democracia ateniense de tornar seu editos disponíveis ao cidadão na acrópole ou na ágora. Assim, Moles acredita que a associação que se pode fazer, nesse caso, é entre a História da Guerra do Peloponeso e as inscrições de

\footnotetext{
${ }^{12}$ Para os propósitos deste artigo, é irrelevante a discussão sobre o fato de A Demônico ser ou não de autoria de Isócrates.

${ }^{13}$ Outras ocorrências de ktema em metáforas semelhantes ocorrem em Sófocles, Édipo Rei, 548-549, e em Isócrates, A Demônico, 6 , e A Nicocles, 5 - todas em contextos de máximas.

${ }^{14}$ Para Svenbro, a palavra nomos ('lei') sozinha teria, etimologicamente, relação com apresentação oral - o que se deve às ocorrências do verbo nemo com o sentido de 'ler', i.e. 'distribuir oralmente' algo (1988, p. 123 e ss.).

${ }^{15}$ Dionísio de Halicarnasso, Demóstenes, 10.3: ho de rhetor tou te arkountos stokhazetai kai tous kairous symmetreitai ouk eis anathema kai ktema ka<taskeuazon> ten leksin monon hosper ho syngrapheus, alla kai eis khresin (apud Moles, 1999) (O orador tem em vista o que é suficiente e compara os momentos oportunos, elaborando o estilo para sua obra servir não como monumento e possessão somente, como o escritor de prosa, mas também para o uso). Na comparação que Dionísio faz entre Tucídides

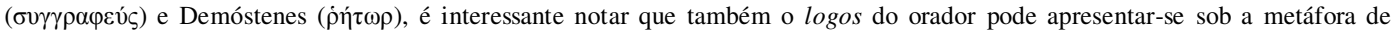
ktema (ouk eis anathema kai ktema....monon,... alla kai...).

${ }^{16}$ Moles lista bibliografia sobre a discussão acerca de como Hecateu, Heródoto e Tucídides apresentam suas obras como uma inscrição (1999, seção 8, n. 32). Bakker desenvolve mais claramente o argumento sobre o aoristo de inscrições associado a $\xi v v \varepsilon ́ \gamma \rho \alpha \psi \varepsilon$ na história tucidideana, embora ele esteja investigando o efeito inscricional das combinações de aoristo com expressões dêiticas. Bakker (2006, p. 114-115) mostra que os enunciados formulares de Tucídides sobre o final de cada ano de guerra, tal qual

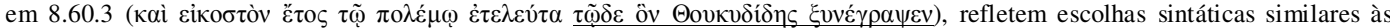

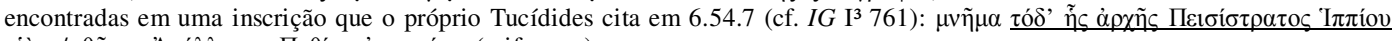

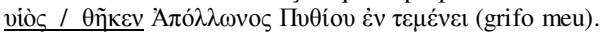


estado (Moles, 1999). Quero acrescentar a esse argumento um elemento que o próprio Tucídides nos fornece e que Moles não examinou: as outras ocorrências de synkeimai na obra tucidideana.

\section{ГYГKEIMAI}

O uso de synkeimai pode estar evocando a sobriedade e a possessão duradoura que as leis registradas em pedra representavam para a polis, especialmente se considerarmos que tal combinação segue imediatamente as advertências de Tucídides quanto ao to me mythodes. A escrita tucidideana não deve ser tomada para entretenimento, mas ser vista tão seriamente quanto os textos das leis e decretos gregos ${ }^{17}$ - aos quais, sugestivamente, Tucídides se refere usando o mesmo verbo: synkeimai. Das 13 ocorrências desse verbo na obra - excluída a de 1.22 -, oito referem-se a termos de tratados ou acordos (cf. 3.70.2, 4.23.1, 5.25.2, 5.47.8, 5.47.12, 8.43.3, 8.52.1, 8.58.5), aparentemente todos escritos, como é seguramente o caso de 5.47.8, cujo decreto é citado verbatim ${ }^{18}$. Cinco estão relacionadas a acordos orais, essenciais às ações políticas e militares: o acordo entre Atenienses e os traidores de Mégara em 4.68.5 para a invasão ateniense da cidade (duas ocorrências de synkeimai nesse trecho); o plano entre Brasidas e os traidores de Torone para a ocupação espartana da cidade em 4.111.1; os relatos sobre atenienses que se dirigiam à Sicília em 6.36.2; e um plano possivelmente prearranjado por Hegesandridas para navegar de Mégara ao longo da costa de Salamina em 8.94.2. Cada vez que Tucídides usa o verbo synkeimai é para designar palavras solenes, i. e. comprometimento verbal, embora não necessariamente escrito, termos que tinham de ser considerados rigorosamente para o bom desenvolvimento das ações subsequentes.

Considerado nesse contexto, o verbo synkeimai em 1.22.4 pode estar reforçando a mensagem subliminar ao leitor-ouvinte de que o texto que deve espelhar o valor e a importância da obra de Tucídides é o texto da lei, que instruía a vida grega em comunidade. Isso faz todo o sentido, se nós acrescentarmos a isso a utilidade, postulada por Tucídides, de sua história. Tucídides espera que seus leitores julguem sua história útil para o entendimento de eventos que, similarmente aos que ele descreve, ocorrerão no futuro novamente, dada a natureza humana. Como os termos de um texto legal ( $\tau \grave{\alpha} \sigma v \gamma \kappa \varepsilon \mu \mu \mu ́ v \alpha)^{19}$ são abertos ao conhecimento do público na acrópole, para que a cidade e o cidadão os utilizem na resolução de conflitos públicos e privados, assim também o texto de Tucídides é concebido como uma aquisição a ser lida por aqueles que

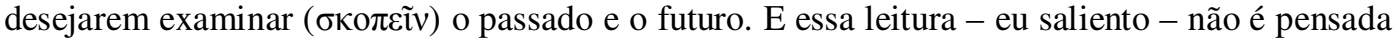
como leitura silenciosa, mas em voz alta.

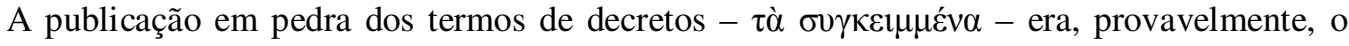
formato mais ordinário de se divulgar textos oficiais da polis no século V. Foi somente na última década do século que um arquivo central foi estabelecido em Atenas - o Metroön -, inaugurando um período de relativa centralização de documentos públicos. A escrita de importantes assuntos da cidade sobre rocha certamente tinha um impacto que não era sentido no caso de tabletes de madeira ou papiros. O valor simbólico atribuído oficialmente às stelai é perceptível, por exemplo, a partir do local onde costumavam ser erigidas, a maioria delas na acrópole - o coração da polis ateniense e seu santuário religioso. Liddle verificou que, em um corpus de 1.679 decretos atenienses do século V ao III que continham referência a local de depósito, $89 \%$ deveriam ser depositados na acrópole. Embora a ágora como local público permitisse publicação fácil e imediata, as stelai com disposições para serem fixadas na ágora tinham de ter seu contéudo de algum modo relacionado à vida da ágora. Mas, embora em menor quantidade, observe-se que havia stelai na ágora também, de modo que os cidadãos poderiam vê-las freqüentemente (Liddle, 2003). Quando utilizada no tribunal, a lei inscrita em uma stele

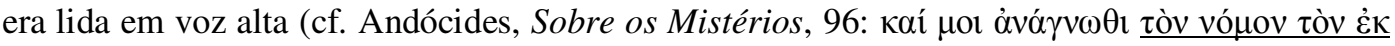

\footnotetext{
${ }^{17}$ Isso talvez expresse um ideal, uma vez que nós podemos ver que o texto de Tucídides testemunha a fragilidade dos acordos escritos, em período de Guerra, que freqüentemente duram, na realidade, menos tempo do que se pretendia que durassem.

${ }^{18}$ Esse decreto foi encontrado em sua forma epigráfica, fragmentada (Hornblower, 2008, p. 110).

${ }^{19}$ Cf. Tucídides: $3.70 .2,5.23 .2,5.47 .8,5.47 .12,8.58 .5$.
} 


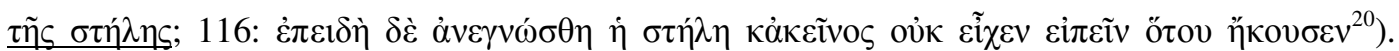
Além disso, o código de leis de Sólon requeria que uma nova lei, depois de ter passado pelos procedimentos com os nomothetai, fosse exibida defronte das estátuas dos heróis epônimos, e lida em voz alta pelo grammateus repetidas vezes nas Assembléias. A razão era que o cidadão pudesse ouvir a lei mais de uma vez e aprender seu conteúdo com tempo e tranqüilidade, de

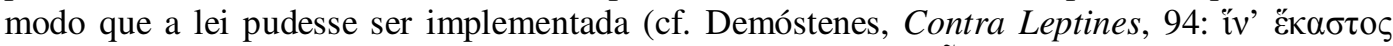

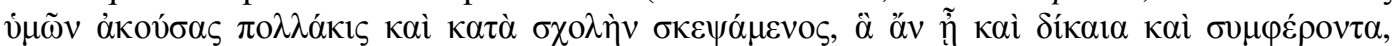
$\tau \alpha \tilde{\tau} \tau \alpha$ vo $\mu 0 \theta \varepsilon \tau \tilde{\eta})$. Ora, se uma nova lei tinha de ficar em frente das estátuas dos heróis epônimos e, além disso, o grammateus precisava ainda lê-la muitas vezes ( $\left.\pi \mathrm{o} \lambda \lambda \lambda_{\alpha} \kappa ı \varsigma\right)$, isso nos permite inferir que os atenienses não se importavam muito em ler as leis antecipadamente. Sua exibição junto às estátuas talvez fosse até mais simbólica que funcional ${ }^{21}$, já que tinham de ser trazidas à ekklesia para serem lidas em voz alta. Somente então elas iriam adquirir alguma utilidade. Não seria essa imagem de ler em voz alta um texto solene, de conteúdo estável e duradouro, a que evocam ktema, akouein e synkeimai em Tucídides?

Enquanto atitudes diferentes com relação a documentos parecem ter surgido com o Metroön, a confiança na leitura oficial continua sendo um traço da publicação de textos legais. Thomas salienta que, quando, no século IV, Licurgo fez provisões legais para manter os textos dos

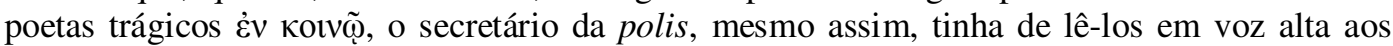
atores para evitar a possibilidade de que estes encenassem um texto distante do oficial (Thomas, 1989, p. 49). Compare-se isso com a função dos exegetai atenienses, que, a partir do século IV, passaram a ser oficialmente responsáveis por comunicar, de memória, as leis sagradas a quem quer que os consultasse. Svenbro pode estar correto ao postular que eles não faziam exatamente uma exegese, no sentido moderno desse termo, como "interpretação", mas tinham a função, basicamente, de pronunciar em voz alta o conteúdo das leis, quase como se estivessem lendo-o de algum lugar em sua memória (Svenbro, 1988, p. 130 e ss.). A audiência imediata de Tucídides, certamente reflexiva, como propõem vários acadêmicos (Edmunds, 1993; Crane, 1996; Yunis, 2003; Yaginuma, 1995), não deve ter estranhado o resíduo aural em 1.22 2 . A

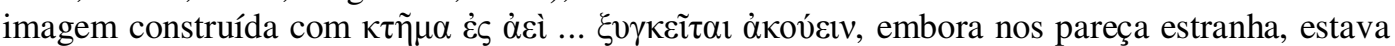
firmemente estabelecida nas práticas de leitura de inscrições da vida política de Atenas.

Yunis, ao tratar dos discursos em Tucídides, acredita que o aumento de textos escritos no período requeria novas habilidades intelectuais, bastante diferentes das usadas na recepção de textos apresentados em performances orais: "For written texts that have subtle didactic aims and require the reader to exercise critical thinking, as is the case with the texts of Thucydides and Plato, the reader's interpretative problem becomes acute" (Yunis, 2003, p. 190). Isso talvez seja verdade, se admitirmos que o raciocínio crítico mencionado por Yunis tenha-se desenvolvido por meio de memorização e discussões orais. Certamente, a liberdade para improvisar sobre as palavras de outrem devia estar diminuindo, uma vez que utilizar um texto escrito como base para discussão requer uma memória mais precisa, algo mais fiel às palavras escritas; mas não estamos ainda em tempos de se retirar um rolo de papiro da bolsa sempre que uma questão se colocasse, pois a fragilidade do papiro simplesmente não resistiria a tal uso ${ }^{23}$. O inteiro debate entre Ésquilo e Eurípides nas Nuvens, de Aristófanes, revela agudo criticismo de cada um deles sobre a obra do outro, mas o conhecimento que demonstram de detalhes de expressões utilizadas pelo adversário parece provir de memorização. Assim, o leitor crítico de Tucídides não é mais crítico do que o seria como ouvinte de Eurípides, uma vez que as tragédias deste objetos de performances orais - também tinham, aparentemente, o propósito explícito de fazer a

\footnotetext{
${ }^{20}$ Grifo meu.

${ }^{21}$ Quanto ao valor de inscrições públicas como memoriais ou símbolos de honra, ver Thomas (1989: 49).

${ }^{22}$ Como bem diz Luragui, "Although writing for eternity, Thucydides, as every author in every time, could not escape conceiving of his implied audience as very similar to his real audience" (Luragui, 2000, p. 227).

${ }^{23}$ Embora Yunis não postule explicitamente um leitor silencioso para a história de Tucídides, seus argumentos sugerem uma certa crítica textual que, de algum modo, requer que o leitor folheie o texto para frente e para trás, de modo similar ao que fazemos hoje (1998, p. 239; 2003, p. 200 e ss.).
} 
audiência refletir, como sugere Aristófanes (Nuvens, 971-975 ${ }^{24}$ ). Não importa quão ironicamente consideremos as palavras do comediógrafo, trata-se de inquietações que parecem ter estado em voga na época, com relação a um público passivo e pouco questionador, de modo que a preocupação com raciocínio crítico não é, portanto, exclusiva dos autores de prosa. Obviamente, a habilidade reflexiva de gregos como Tucídides desenvolvera-se principalmente por meio de leituras em voz alta ${ }^{25}$, boa memória, e discussão, não pela relação silenciosa e abstrata com a escrita. No Fedro, Sócrates não lê o discurso de Lísias com seus próprios olhos e voz, mas ouve a leitura de Fedro (230e6: 'Aкоvє $\delta \eta ́)$ e, em seguida, inicia uma longa crítica a partes específicas selecionadas por ele durante uma única audiência. Sócrates ainda menciona detalhes formais do texto: as expressões de Lísias são claras e arredondadas, cada uma delas

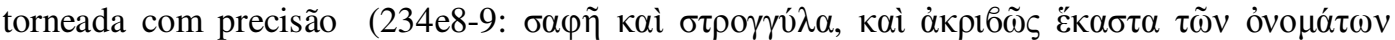

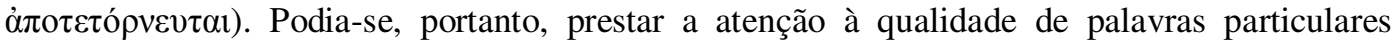
simplesmente por tê-las ouvido, sem necessariamente ter de vê-las escritas. Isso talvez ainda tivesse relação com o custo ou pequeno número de cópias em circulação. No século IV, mesmo um profissional do logos como Isócrates podia julgar necessário submeter seus discursos a uma publicação oral primeiro, para decidir se eram dignos ou não de serem divulgados depois por meio escrito. Isócrates nos informa de uma ocasião em que, primeiro, apresenta o texto a amigos para que avaliem se está adequado ou não à divulgação escrita (Panatenaicos, 233):

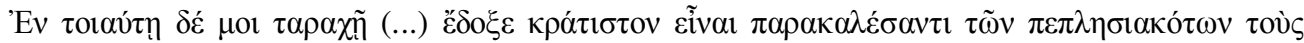

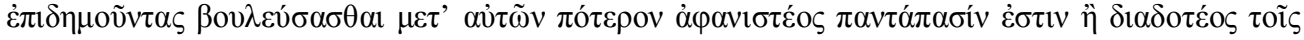

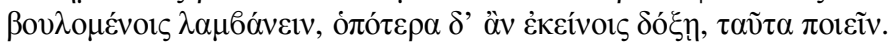

Em minha confusão (...), pareceu-me melhor que aqueles meus discípulos que moram na cidade viessem a meu chamado para eu deliberar com eles se o discurso deveria ser destruído ou distribuído a todos que o desejassem ter, e qualquer quer fosse a opinião deles, segui-la.

Se as cópias de um discurso circulavam em número reduzido, então faz todo o sentido tê-lo pré-publicado para amigos antes de se despender muito esforço para colocar outras cópias em circulação ${ }^{26}$. No contexto da Grécia clássica, quando pensamos em um leitor-ouvinte crítico, devemos também considerar que esse leitor, em geral, precisa concentrar-se bastante no que está sendo ouvido, e confiar em sua memória; ao mesmo tempo, ele tem de desenvolver uma relação rápida com o que está ouvindo para ser capaz de ponderar e tomar decisões, concordar ou discordar com o que ouve. Um comportamento crítico normalmente é função de diferentes fatores que interagem na educação e experiência de um indivíduo. Gregos educados para ser políticos e intervir ativamente na assembléia seriam mais ou menos críticos em diferentes graus, e Tucídides revela-se ciente disso.

\section{CONSIDERAÇÕES FINAIS}

Embora pareça sedutor pensar o leitor de Tucídides como um intelectual acostumado a enrolar e desenrolar rolos de papiro para checar qualquer estranha repetição de palavras nos discursos, ou trecho ambíguo, este provavelmente não era o caso. A metáfora em 1.22, $\kappa \tau \tilde{\eta} \mu \alpha$

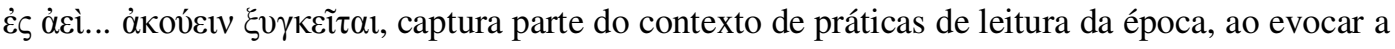
cena de pessoas que lêem em voz alta textos inscritos em rochas, cujo conteúdo deve permanecer no tempo e proporcionar instrução, em contraste com o conteúdo dos textos de logógrafos, para performance, a serem lidos para divertir ou entreter as audiências em um dado momento.

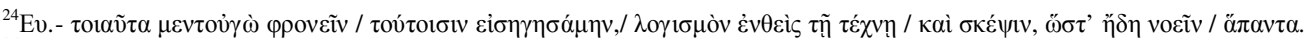

${ }^{25}$ Compare-se isso com práticas de leitura no século XVIII. Na peça de Marivaux Love's Second Surprise, um dos personagens havia sido contratado pela marquesa para atuar como seu leitor particular: "Two weeks ago I took on a man to whom I have entrusted my library, I do not flatter myself that I will become a scholar, but I am eager to occupy my time. He reads me something every evening. Our readings are serious and reasonable" (Chartier, 2002, p. 137).

${ }^{26}$ Thomas sugere que leituras públicas eram também um modo barato para a circulação de livros (Thomas, 2003, p. 166).
} 
O texto de Tucídides, uma vez sujeito à leitura em voz alta, pode ter inspirado diferentes tipos de leitura, algumas mais entusiásticas, outras mais sérias e reservadas, conforme os diferentes momentos da narrativa. Ler a passagem conhecida como arqueologia da Sicília pode ter causado bastante enfado, ao passo que a narrativa sobre a partida da expedição ateniense para a Sić́lia, no livro 6, até hoje nos deixa emocionados face a tão bela expressão de linguagem. A troca de palavras ríspidas entre Nícias e Alcibíades pode facilmente ter estimulado um certo tipo de performance, particularmente se lembrarmos que tais figuras permaneceram populares no imaginário grego por muito tempo, como testemunham as biografias de Plutarco. No final, apesar das palavras de Tucídides em 1.22, trechos de sua história podem permitir leituras bastante prazerosas, como todos os seus leitores bem sabem. De fato, Tucídides visava, certamente, a um leitor reflexivo, mas esse leitor estava provavelmente emergindo menos do desprezo por performances orais como meio de recepção de textos do que de um conjunto de circunstâncias políticas, que estariam deixando os indivíduos mais críticos em relação ao que estavam ouvindo. A manipulação de assembléias por parte de alguns líderes, a descrença na correção dos tribunais, e a difusão de aulas de sofística devem ter influenciado os cidadãos atenienses a buscarem, naturalmente, uma atitude mais analítica diante das palavras de outrem. O tipo de prosa praticada por Tucídides, que demandava grandes habilidades de memória ou mesmo conhecimento prévio para preencher lacunas de informação, era apenas um outro fator a contribuir para o desafio às mentes passivas, algo que, no mundo grego, já havia sido antecipado por Parmênides (em verso!) e Heráclito.

\section{BIBLIOGRAFIA}

BAKKER, E. J. Contract and Design: Thucydides' writing. In: RENGAKOS, A.; TSAKMAKIS, A. (orgs.) Brill's Companion to Thucydides. Leiden: Brill, 2006.

CHANTRAINE, P. La formation des noms en Grec Ancien. Paris: Librairie Ancienne Honoré Champion, Éditeur Édouard Champion, 1933.

CHARTIER, R. The practical impact of writing. In: FINKELSTEIN, D.; MCCLEERY, A. (orgs.) The Book History Reader. Londres e Nova Iorque: Routledge, 2002.

COOPER, G. L. Attic Greek prose syntax. Ann Arbor: University of Michigan Press, 1998.

CRANE, G. The Blinded Eye: Thucydides and the New Written Word. Lanham: Rowman \& Littlefield, 1996.

EDMUNDS, L. Thucydides in the act of writing. In: PRESTAGOSTINI, R. Tradizione $e$ Innovazione nella cultura Greca da Omero all' eta Ellenistica. Roma: Gruppo Editoriale Internazionale - GEI, 1993.

FLORY, S. Who Read Herodotus' Histories? American Journal of Philology, v. 101, n.1, p. $12-$ $28,1980$.

HORNBLOWER, S. A Commentary on Thucydides. Volume I: Books I-III. Oxford: Clarendon Press, 1991.

A Commentary on Thucydides. Volume III: Books 5.25-8.109. Oxford: Oxford University Press, 2008.

KAHN, C. H. Writing Philosophy. Prose and Poetry from Thales to Plato. In: YUNIS, H. Written texts and the rise of literate culture in Ancient Greece. Cambridge: Cambridge University Press, 2003.

LIDDLE, P. The Places of Publication of Athenian State Decrees from the $5^{\text {th }}$ Century BC to the $3^{\text {rd }}$ Century AD. Zeitschrift Für Papyrologie Und Epigraphik, v. 143, p. 79-93, 2003.

LURAGUI, N. Author and Audience in Thucydides' Archaeology. Some Reflections. Harvard Studies in Classical Philology, Harvard, v. 100, p. 227-39, 2000.

MOLES, J. Anathema and ktema: the Inscriptional Inheritance of Ancient Historiography. Histor, v. 3, 1999. Disponível em: http://www.dur.ac.uk/classics/histos/1999/moles.html.

PELLING, C. Literary Texts and The Greek Historian. Londres e Nova Iorque: Routledge, 2000.

Organon, Porto Alegre, n 49, julho-dezembro, 2010, p.203 - 218 
SVENBRO, J. Phrasikleia. Anthropologie de la lecture en Grèce Ancienne. Paris: Éditions La Découverte, 1988.

THOMAS, R. Herodotus in Context. Cambridge: Cambridge University Press, 2000.

THOMAS, R. Oral tradition and written record in classical Athens. Cambridge: Cambridge University Press, 1989.

THOMAS, R. Prose Performance Texts: Epideixis and Written Publication in the Late Fifth and Early Fourth Centuries. In: YUNIS, H. Written Texts and the Rise of Literate Culture in Ancient Greece. Cambridge: Cambridge University Press, 2003.

THUCYDIDE. Histoire de la Guerre du Péloponnèse, traduction. Introduction, notes par Jacqueline de Romilly. Paris: Laffont, 1990.

THUCYDIDES. History of the Peloponnesian War. Translated with an introduction by Rex Warner and notes by M. I. Finley. Londres: Penguin Books, 1990.

THUCYDIDES. History of the Peloponnesian War. Translated by R. Crawley. Londres, Vermont: Everyman, 1993.

THUCYDIDES. The Peloponnesian War. Translated by T. Hobbes, with notes by D. Green. Chicago, Londres: The University Chicago Press, 1989.

THUCYDIDES. History of the Peloponnesian War. Translated, with introduction, notes, and glossary by Steven Lattimore. Indianapolis, Cambridge: Hackett Pub. Co., 1998.

TUCÍDIDES. História da Guerra do Peloponeso. Livro I. Tradução e apresentação de Anna Lia Amaral de Almeida Prado. São Paulo: Martins Fontes, 1999.

YAGINUMA, S. Did Thucydides Write for Readers or Hearers? In: AYRES, L. The Passionate Intellect. Essays on the Transformation of Classical Traditions. New Brunswick e Londres: Transaction Publishers, 1995.

YUNIS, H. Writing for reading. Thucydides, Plato, and the emergence of the critical reader. In: Written texts and the rise of literate culture in Ancient Greece. Cambridge: Cambridge University Press, 2003.

YUNIS, H. The Constraints of Democracy and the Rise of the Art of Rhetoric. In: D. BOEDEKER, D.; RAAFLAUB, K. A. Democracy, Empire, and the Arts in Fifth-Century Athens. Cambridge, Londres: Harvard University Press, 1998. 